\title{
Questionnaire survey of removable prosthetic treatment in children
}

\author{
Desislava Dimitrova
}

1. Dental Clinic "Edinstvo", Sofia, Bulgaria;

\begin{abstract}
Prosthetic treatment with removable prosthesis is necessary in cases of genetic and hereditary diseases, multiple caries and severe traumas in order to restore effective chewing and speech function, to achieve acceptable appearance and to ensure unimpeded development of the oral structures and the whole organism. The purpose of the study is to investigate the use of removable prosthetic treatment in children in the daily practice of dentist in Bulgaria. Material and methods: A source of information is a specially designed questionnaire. 767 doctors from all over the country are subjected to the research. The results are statistically processed using the methods of variation, comparison and correlation analysis. Results: Of all respondents, only $0.4 \%$ indicated that they use/ or used total dentures in children, and $4.2 \%$ note that they are using partial prostheses as a means of restoring of the disturbances. Conclusion: Partial and total edentulism is a rare problem in young patients, which also determines the sporadic use of removable prostheses in daily practice by dental practitioners.
\end{abstract}

Keywords: removable prosthetic treatment, childhood, application 


\section{Introduction}

The use of methods of removable prosthetic treatment at all ages requires satisfaction of the three mediobiological indicators. Successful treatment should perform a prophylactic function with respect to prosthetic field, surrounding tissues and oral hygiene [1, 2], to adequately restore speech and chewing function $[3,4]$ and to achieve excellent results in aesthetic and natural appearance of patients $[5,6,7]$. Prosthetic treatment with removable constructions in childhood is characterized with peculiarities, which are of scientific interest. Various genetic diseases, multiple caries and severe traumas can result in partial or complete tooth loss in children [8]. The disturbances in oral structures results in ineffective chewing function and violation of the basic vital processes such as eating and speaking $[9,10,11]$. The interferences in appearance and sound articulation often lead to emotional and social problems [12]. According to Tarjan et al. [13] the long-term neglect of these problems can lead to disturbances in mental development even at early age.

Removable prosthetic treatment as a method of oral rehabilitation in young patients should be given special attention due to the continuous growth processes and the age-related anatomical, physiological and psychological characteristics [14].

There are literature sources $[15,16,17,18,19,20]$ that discuss the successful use of removable partial, total dentures and overdentures in different ages. Although it is considered [8] to be an inadequate alternative to a healthy child dentition they provide the possibility of restoring chewing function and effectiveness within normal limits; achievement of occlusal-articulation balance; creating the right conditions for proper sound extraction; improving the appearance of children and ensuring optimal growth of facial and jaw bones.

All this necessitates the need of a contemporary study of the modern methods of restorative and prosthetic pediatric dental medicine.

\section{Aim}

The aim of the present study is to determine the extent of application of total and partial prostheses in childhood, based on the subjective assessment of dentists in Bulgaria.

\section{Material and methods}

Material and Methods: From October 2017 to April 2018, a survey of 767 dentist is randomly conducted. Object of observation is the application of the total and partial dentures in childhood.

A source of information is an anonymous questionnaire, containing general section that provides information on the location of dental practice, gender, age, length of service and the presence of a specialty by dentist. Six of the questions investigate the clinical experience of the responders with regard to restorations with removable prosthetic constructions in childhood: 
1. Do you provide treatments in children with the methods of the prosthetic dentistry?

$$
\text { Yes } \square \text { No }
$$

2. Do you provide prosthetic treatment with removable dentures in children?

Yes $\square$ No

3. What kind of removable prosthetic construction do you use in childhood?
total dentures
partial dentures

4. How often do you provide prosthetic treatments with different removable dentures in childhood?
more than once a month
once a month
once every three months
once every six months
once a year
less than once a year

5. What is your assessment of the need for treatment with removable prosthetic constructions in childhood?

$\square$ I have never met such clinical cases in my practice

I rarely met such clinical cases in my practice

I often met such clinical cases

6. According to your clinical experience, does the prosthetic treatment with removable dentures satisfy the requirements of the children and their parents regarding:

- the prophylactic medical-biological indicator:

$\square$ Yes $\square$ No

- the functional medical-biological indicator:

speech function $\quad \square$ Yes $\square$ No

chewing function $\quad \square$ Yes $\square$ No

- aesthetic medical-biological indicator

Yes $\square$ No

I have not conducted such a study 
The results are statistically processed with the packet of software programs for data analysis from epidemiological and clinical studies - SPSS for Windows, version 22.0.0. The methods of statistical processing used are: descriptive analysis, variance analysis, correlation analysis, queries for quantification of qualitative variables via chi-square and Fisher's precise (two-tail) test and multivariate analysis. MS Excel 2010 is used for graphical presentation of the results.

\section{Results}

After analyzing the data obtained, it was found that the average age of dentists, took part in the questionnaire is $45.9 \pm 13.1$ years. Women (61.5\%) and respondents with over 10 years of experience (69.1\%) prevail. Despite the fact that the majority of the dentists surveyed have a long experience, the significant part is without specialty (62.7\%). Of the persons with specialty, those with "General dentistry" predominate $(49.7 \%)$.

Only $10.6 \%$ (81 people) of all respondents indicated that they place prosthetic restorations in the treatment of the small patients. Male dentists are more likely to use the potential of prosthetic treatment in pediatric dentistry $(x 2=4.00, P=0.031)$. The likelihood of men using prosthetic constructions in the treatment of children is 1.30 to 0.82 for the women.

The presence of specialty has an impact on the use of prosthetic restorations in children, as the dentist with specialty has a higher proportion in the use of this type of treatment $(15,60 \%)(x 2=10,55, p=0,001)$. The dentists with specialty of pediatric dentistry $(23.0 \%)$ and prosthetic dentistry $(23.8 \%)$ have the highest proportion of prosthetic treatments performers $(x 2=10.20, P=0.037)$.

The factors age and length of service have no significant impact on the use of prosthetic constructions in small patients.

In the analysis of the data, we found extremely low frequency of distribution of the respondents, which apply restorations with removable dentures in childhood - 4.7\% (35 persons). Of the dentists, which indicate that they use the methods of removable prosthetic treatment, predominate those of the male gender (65.7\%), with a specialty in Prosthetic dentistry (37.1\%) and Orthodontics (34.3\%) and over 10 years of experience (57.1\%).

In the study of the type of removable dentures used, it was found that $3(0.5 \%)$ of all respondents indicated that they are placing/ or placed total dentures in children. Twenty-two (4.2\%) of the dentists indicate that they are/were using partial dentures as a method of restoring the disturbances of dental arches in young patients.

Of the dentists recovering the defects in the oral structure of the children with partial removable dentures, $59.4 \%$ have a specialty $\left(X^{2}=6.96 ; P=0.014\right)$, as the prevalence is for those with specialty in Prosthetic dentistry $(9.50 \%)$, followed by those with specialty Orthodontics $(7.0 \%)$. Of the specialist in pediatric dentistry, treatment with partial dentures, use only $1.6 \%$ of the respondents $(X 2=13.06 ; P=0.011)$.

Of the surveyed dentists, $3.7 \%$ said they had prosthetic treatments with removable prosthetic constructions less than once a year and $2.4 \%$ once a year. 
The analysis of the answers of the question "What is your assessment of the necessity of treatment with removable prosthetic constructions in childhood?" shows that a significant proportion of dentists (79.8\%) have not met in their practice clinical cases requiring partial or total removable dentures. The relative share of respondents who testify that they rarely experience similar clinical cases in their day-to-day practice is $15.6 \%$. There is a statistically significant dependence $(P<0.001)$ between the answers of question 5 and question 6 . A significant proportion of the dentists, who have reported that rarely met in their clinical practice partial or total edentulism in children, also testify that they have been performing prosthetic treatment with removable prosthetic structures less than once a year.

A significant proportion of the dentists (82.4\%) which use the methods of prosthetic treatment with partial and total dentures for recovering the defects in temporary or permanent dentition did not conduct study on child and parent satisfaction with all the three medical -biological indicators. Treatment with removable prosthetic constructions meets patient requirements in terms of the prophylactic indicator, according to $64.5 \%$ of the dentists and the aesthetic indicator according to $81.3 \%$ of the dentists. When considering the functional medical-biological indicator, $69.7 \%$ believe that total and partial dentures fully meet the expectations of the children and their parents. The relatively low proportion of the dentists (41.3\%), who consider that the removable dentures does not meet the requirements for speech function, makes an impression.

\section{Discussion}

A significant part of the dentists (89.4\%) indicate that they did not use the methods of prosthetic dentistry in childhood. There are a number of scientific data available in world literature $[21,22,23,24,25]$ which testify for the use of different types of ready-made and laboratory-made crowns, veneers and implant prosthetic restorations in patients under 16 years of age. In our country Dimitrov [26] review in details the treatment of carious defects by the use of preformed metal crowns with Hall technique. Other foreign authors [27, 28, 29] prove the successful recovery of the highly destroyed teeth with ready-made zirconium crowns. The data $[30,31]$ on the application of fixed prosthetic restorations in the day-to-day work confirms their rare use by the dentist.

Despite the scientific data $[32,33,34]$ that demonstrate the successful recovery of the three medio-biological indicators with the use of removable dentures in children with various genetic, hereditary and acquired diseases, studies on the application of this method in day-to-day practice are still scarce. In our study, it was found that a large proportion of dentists use partial or total dentures once or less than once a year. In addition, most of the responders indicate that clinical cases, requiring treatment with removable dentures, rarely occur in their practice. The obtained results match with the rare prevalence of hypodontia and anodontia in the period of primary dentition - between 1 and $4 \%$ of the total population [35].

The impression is made by that a large number of dentists (82.4\%) say that they are conducting treatments without examining the patient's satisfaction with the results. According to the subjective assessment of the respondents, the methods of removable prosthetic treatment meet the requirements of the children and their parents regarding the aesthetic and prophylactic medical-biological indicators. Only in view of the functional indicator, $41.3 \%$ of the dentists believe that the partial and total dentures do not meet the patients' expectations regarding speech function. These results point to the need of a study of sound reproduction 
and acoustic articulation before, immediately after and at the end of the adaptation period, through a series of established logopedic tests, that can be applied briefly in clinical practice [36].

\section{Conclusion}

The analysis of application of prosthetic restorations in the population of dentists in Bulgaria shows that the percentage of dentists, which indicate that use these methods of treatment in children ranges from $3.6 \%$ to $5.9 \%$ ninety five percent confidence interval. The need of a treatment with total and partial removable constructions is sporadic, with probable reasons for this being the rare problem and good prevention of partial and / or total edentulism in children, as well as the necessity of a multidisciplinary approach, consultation with other professionals and a detailed knowledge of the stages of planning, making and modifying the removable dentures.

\section{References}

1. Peev T, Filchev A. Clinic of prosthetic dental medicine. (in Bulgarian). Publisher: EkoPrint 2008 book.

2. Yankova M, Yordanov B, Baykuchev R, Raykova V, Mitov I. Presence of Candida spp. in the saliva of patients with complete dentures, lined with silicone-based elastic materials. J of IMAB. 2017 OctDec;23(4):1813-1822.

3. Konstantinova D, Dimova M. Choice of food sample in examining the masticatory function in edentulous patients and in patients with removable dentures, Scripta Scientifica Medica. 2013; 45(3) 27-31.

4. Dimova M, Hadjieva H, Peev T. Individual transferring of clinical and paraclinical data by total rehabilitation of patients with compromised stability of the full dentures. A pilot study. Journal of IMAB - Annual Proceeding (Scientific Papers) 2005; 11(2): 43-45

5. Dimova M, Yankova M, Peev T. Questionnaire of laboratory modeling in the fabrication of total dentures. Problems of dentistry. 2008; XXXIV (II): 43-49.

6. Yankova M, Dimova M, Peev T. Method for laboratory determination of the shape of the upper frontal teeth in total prosthetic treatment (pre-release message). Scientific Researches of the Union of Scientists in Bulgaria - Plovdiv 2007, Series B. Natural Sciences and the Humanities. 2008; IX: 165-170.

7. Hadzhieva X, Dimova M, Peev T. Clinical accents in total prosthetic treatment of patients with aesthetic problems, XIX regular congress of BNSD 100 years of organized dentistry in Bulgaria, Scientific conference "Prophylaxis and treatment of dental diseases", Sofia, 30 September - 1 October 2005, Collection of Abstracts, 45-46.

8. Marques N, Gurgel C, Fernandes A, Lima M, Machado M, Soares S, Oliveira T. Prosthetic rehabilitation in children: An alternative clinical technique. Case Rep Dent. 2013 Sep; 2013: 512951.

9. Yordanov B, Yankova M, Yoncheva I. Assessment the quality of life in patients with removable dentures, lined with soft elastic materials - a pilot study. Infodent Protetik. 2014; 4: 37-45

10. Hadjieva $\mathrm{H}$, Dimova M, Peev $\mathrm{T}$. Total rehabilitation by edentulous patients with irregularity of the alveolar ridges. Journal of IMAB, Annual proceeding (Scientific papers), online, Book 2, Part Dentistry, Publisher Peytchinski-Gospodin Iliev. 2005: 50-52

11. Dimova, M., H. Hadjieva, T. Peev: Oral clinical patient record for observation data of edentulous patients. Dental medicine. 2009; 1: 34-40.

12. Hadjieva $H$, Dimova $M$, Peev T. Clinical procedures contributing to the esthetic result by total denture treatment. Zabolekarski Pregled. 2006; 2: 108-112 
13. Tarjan I, Gabris K, Rozsa N. Early prosthetic treatment of patients with ectodermal dysplasia: A clinical report. J Prosthet Dent. 2005 May; 93(5):419-424.

14. Kościelska N, Bogucki Z. Clinical factors in prosthodontic treatment of children with genetic defects. Adv Clin Exp Med. 2017 Sep;26(6):1005-1012.

15. Vulicevic Z, Beloica M, Kosanovic D, Radovic I, Juloski J, Ivanovic D. Prosthetics in Paediatric Dentistry. Balk J Dent Med. 2017; 21(10): 78-82.

16. Mopagar V, Naik S, Jadhvar R, Raurale A. Complete denture prostheses in an 8-year-old child with hypohidric ectodermal dysplasia. J Pediatr Dent. 2014 Jul; 2(2): 74-77.

17. Maroulakos G, Artopoulou I, Angelopoulou M, Emmanouil D. Removable partial dentures vs overdentures in children with ectodermal dysplasia: two case reports. Eur Arch Paediatr Dent. 2016 Jun; 17(3):205-210.

18. Yankova M, Fetfova D. Fabrication of transitional immediate complete denture. Medlnform. 2016; 3(2):492-498.

19. Dimova M, Hadjieva H, Peev T. Documented data transfer and directions between clinic and laboratory in total prosthetics. Zabolekarski Pregled. 2006; 2: 103-107.

20. Yankova M. Clinical and experimental study of the elastic materials for relining full dentures. PhD Thesis. Sofia 2018

21. Wray A, Welbury R. UK National Clinical guidelines in Paediatric Dentistry. Treatment of intrinsic discoloration in permanent anterior teeth in children and adolescents. Int J Paediatr Dent. 2001; 11(4): 309-315.

22. Kramer F, Baethge $\mathrm{C}$, Tschernitschek $\mathrm{H}$. Implants in children with ectodermal dysplasia: a case report and literature review. Clin Oral Implants Res. 2007; 18(1): 140-146

23. Percinoto C, De Mello Vieira AE; Megid Barbieri C, Lemos Mehlado F, Silva Moreira K. Use of dental implants in children: A literature review. Quint Int. 2001; 32(5): 381-383

24. Garg V, Panda A, Shah J, Panchal P. Crowns in peadiatric dentistry: a review. J Adv Med Dent Scie Res. 2016; 4(2): 41-46

25. Tote J, Gadhane A, Das G, Soni S, Jaiswal K, Vidhale G. Posterior Esthetic Crowns in Peadiatric Dentistry. Int J Dent Med Res. 2015; 1(6):197-201

26. Dimitrov E, Georgieva M, Dimova-Gabrovska M, Andreeva R, Belcheva-Krivorova. Preformed metal crowns as prosthetic restoration in pediatric dentistry. J of IMAB 2017; 23(3): 1627-1632

27. Cohn C. Zirconia-Prefabricated Crowns for Pediatric patients with primary dentition: Technique and cementation for esthetic outcomes. Compend Contin Educ Dent. 2016; 37(8): 554-558

28. Cazaux L, Hyon I, Prud homme T, Trutaud D. Twenty-nine-month follow up of a paediatric zirconia dental crown. BMJ Case Rep. 2017; 2017-219891

29. Bhola $M$, Jindal G. Revolution in pediatric restorative dentistry - zirconia crowns. Journal of Stomatognatic Sciences. 2016; 6(1): 22-26

30. Duggal MS, Curzon MEJ. Restoration of the broken down primary molar: 2. Stainless steel crowns. Dent Update. 1989;16(2):71-75.

31. Threlfall A, Pilkington K, Blinkhorn A, Tickle M. General dental practitioners views on the use of stainless steel crowns to restore primary molars. Brit Dent J 2005; 199(7): 453-455

32. Walsh JF. Pedodontic prostheses. J Prosthet Dent 1976; 36(1):13-16

33. Jain V, Gupta R, Parkash H. Prosthetic rehabilitation in Papillon-Lefevre syndrome: a case report. J Indian SocPedoPrev Dent 2005; 23(2): 96-98

34. Dominguez A, Aznar T. Removavle prostheses for preschool children: Report of two cases. Quint 2004; 35(5): 397-400

35. Caldo-Teixeira A, Puppin-Rotani R. Management of severe partial hypodontia: case report. J Clin Pediatr Dent. 2003; 27(2): 133-136.

36. Dimova-Gabrovska M, Dimitrova D, Mitova M. Investigation of the speech in patients with bruxism. Knowledge International. 2017; 19(4): 1487-1490

\section{Corresponding author:}

Desislava Dimitrova, Email: desislavvva23@gmail.com 